\title{
Rare giant multiglandular parathyroid hyperplasia in type 1 multiple endocrine neoplasia assessed by sestamibi scintigraphy
}

\author{
Amrita Lahoti, Xuexian Yan \\ Department of Nuclear Medicine and PET, Singapore General Hospital, Singapore \\ Correspondence: Xuexian Yan. Address: Department of Nuclear Medicine and PET, Singapore General Hospital, Outram \\ Road, Singapore. Email: sean.yan.x.x@sgh.com.sg
}

Received: December 22, 2015 Accepted: May 23, $2016 \quad$ Online Published: June 7, 2016

DOI : 10.5430/ijdi.v3n2p48 URL: http://dx.doi.org/10.5430/ijdi.v3n2p48

\begin{abstract}
We describe a rare case of 32-year-old male with multiple endocrine neoplasia type 1 (MEN1) gene mutation characterised by extensive parathyroid hyperplasia and pancreatic neuroendocrine tumour. Pre-operative Tc-99m Sestamibi scan showed multiple hyperfunctioning parathyroids which were confirmed intraoperatively to be giant hyperplastic glands and an ectopia in the mediastinum. According to the current guidelines, pre-operative imaging is of limited benefit in MEN1 parathyroid disease, nevertheless this case does demonstrate utility of preoperative Sestamibi scintigraphy in accurately estimating the extent of disease in MEN1. Consequently, it facilitates better surgical planning and decreases the chance of persistent disease.
\end{abstract}

\section{Keywords}

Primary hyperparathyroidism, Multiple endocrine neoplasia type 1, SPECT, 99mTc-MIBI

\section{I ntroduction}

Multiple endocrine neoplasia type 1(MEN1) is an autosomal dominant genetic syndrome characterized by parathyroid, anterior pituitary and pancreatic tumours. In MEN 1, primary hyperparathyroidism (HPT) is the most common presentation with 100\% penetrance by age of 40-50 years. There are unique features in MEN1 related HPT in comparison with sporadic HPT ${ }^{[1,2]}$ : Hyperplasia instead of adenoma is the predominant pathology; multiple gland involvement and earlier onset ${ }^{[2-5]}$; Pre-operative imagings are of limited benefit in MEN1 HPT because all the parathyroids may be affected, and total/sub-total parathyroidectomy is the standard procedure rather than minimally invasive surgery ${ }^{[2,6]}$. However, this approach may miss ectopic/supernumerary parathyroid which is beyond the standard surgical bed therefore could lead to persistent disease. In addition, the surgical process may be unnecessarily prolonged without knowing the exact extent of the disease preoperatively.

\section{Case presentation}

A 32-year-old male presented with elevated serum calcium $13.8 \mathrm{mg} / \mathrm{dl}$ (normal 8.5-11 mg/dl) and PTH 565 pg/ml (normal $10-65 \mathrm{pg} / \mathrm{ml})$. Clinical diagnosis of primary hyperparathyroidism was established. Past medical history was remarkable for 
duodenal ulcer disease on long term proton pump inhibitor. Ultrasonography revealed two solid masses inferior to thyroid lobes. Further evaluation was done with 99mTc-Sestamibi scan as shown in Figure 1. 20 minutes early (A) and 2 hours delayed (B) images revealed persistent tracer uptake in the inferior pole of right and left thyroid lobes (arrow heads in A and B) and a large focus of intense activity in left hemi-thorax (arrows in A and B).

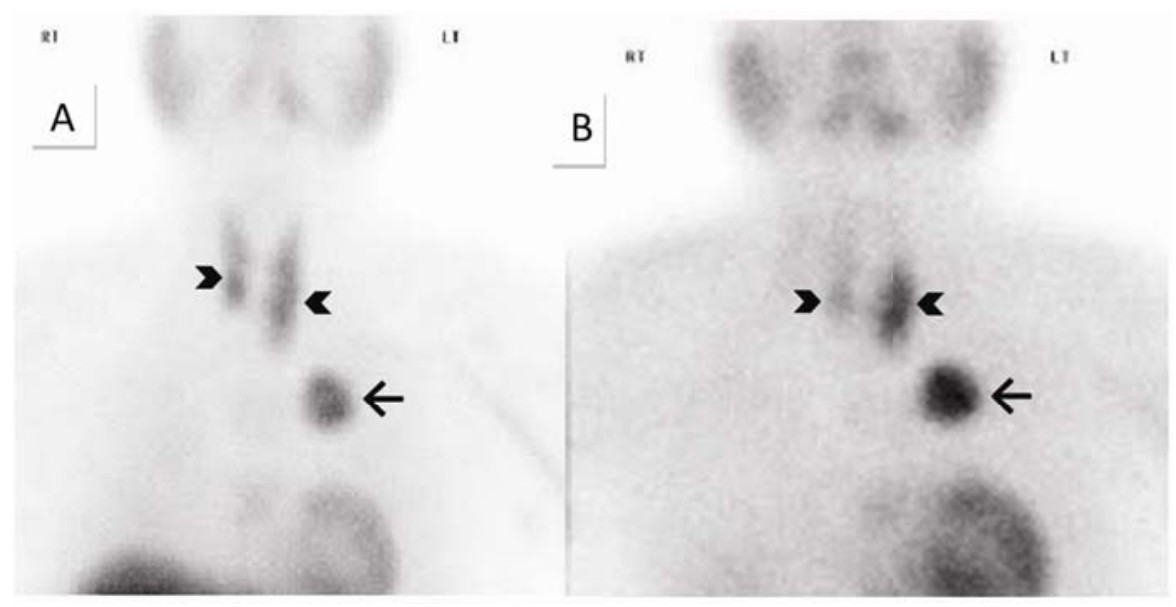

Figure 1. 99mTc-Sestamibi scan planar images of the neck and chest

SPECT/CT imaging shown in Figure 2 demonstrated the left thoracic focus actually corresponding to a soft tissue mass lateral to the aortic arch (arrow in A). The Sestamibi avid soft tissue mass at the inferior pole of the left thyroid lobe extending to para-tracheal region (arrow in B). Ultrasonography guided biopsy confirmed parathyroid hyperplasia. MEN1 mutation was identified on consequent genetic study. Hence, diagnosis of MEN1 associated multiglandular parathyroid hyperplasia was established. Patient underwent sub-total parathyroidectomy through trans-cervical resection. Parathyroid glands were found variably enlarged: 70 minigrams for right superior, 37 grams for right inferior, 24 grams for left superior extending down to the left para-tracheal region and 25 grams for left inferior which was ectopic in left upper mediastinum. Postop histology confirmed parathyroid hyperplasia. Serum calcium and PTH normalized after surgery and remained stable for 3 years on follow-up.

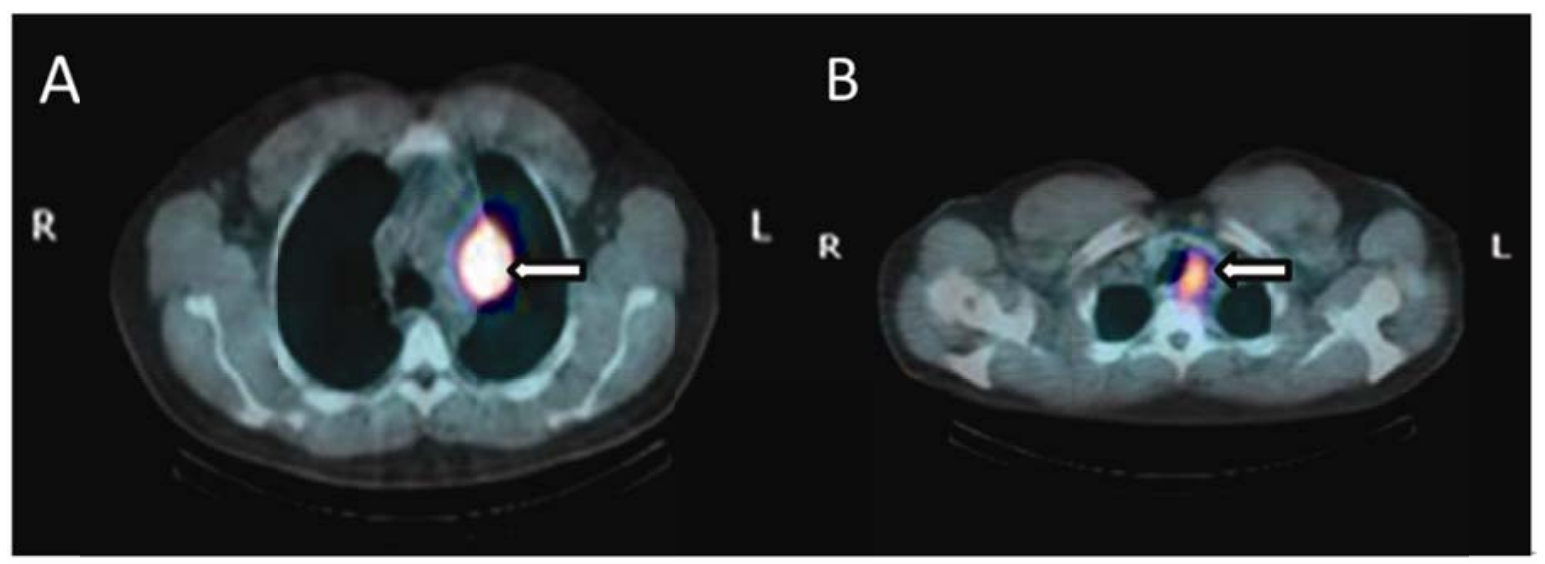

Figure 2. 99mTc-Sestamibi SPECT/CT of the lower neck and thorax

CT abdomen and MRI brain did not show pancreatic or pituitary tumour at the time (images not shown). However 15 months later surveillance CT revealed multiple nodules in the pancreas (see Figure 3, arrows in A and B). Serum gastrin was elevated to $337 \mathrm{pg} / \mathrm{ml}$ (normal $<100 \mathrm{pg} / \mathrm{ml}$ ). Patient had total pancreatectomy. Histological diagnosis confirmed well differentiated gastrinoma. Post-surgery serum gastrin level came down to normal. 


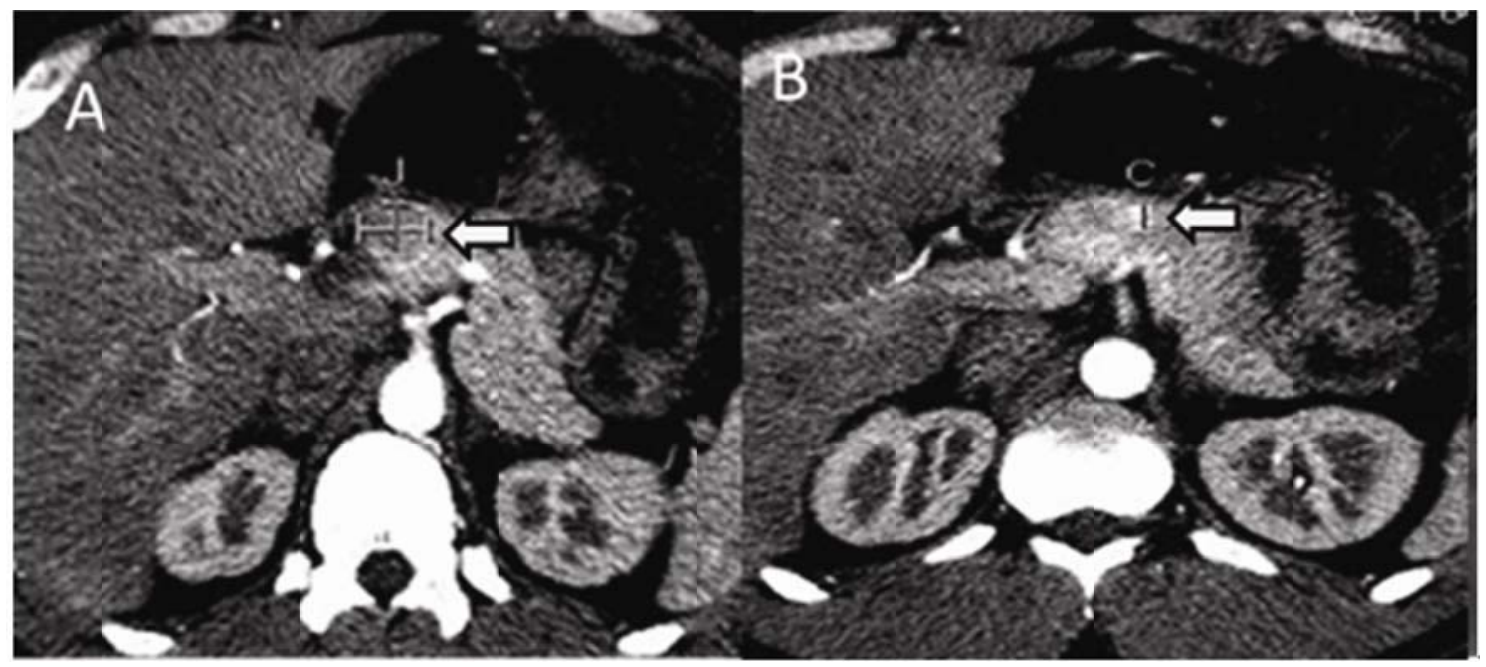

Figure 3. Contrasted CT scan of the abdomen

\section{Discussion}

As shown in this case, preoperative sestamibi scintigraphy can be beneficial to confirm or exclude ectopic/supernumeries and to estimate the extent of disease, thus helps in better surgical planning and in decreasing the rate of persistent disease $^{[7,8]}$, even in the scenario of miltiglandular hyperplasia associated with MEN1.

In MEN1, gastrinoma is the most common pancreatic tumour (60\% of all the cases) and is the leading cause of mortality and morbidity ${ }^{[1,2,9]}$. It is fascinating that pancreatic gastrinoma eventually became evident under surveillance in this patient with a long history of duodenal ulcer disease, retrospectively. It demonstrates the value of long term imaging surveillance in detecting pancreatic neoplasia in MEN1 patients.

\section{References}

[1] Scarsbrook AF, Thakker RV, Wass JA, et al. Multiple endocrine neoplasia: spectrum of radiologic appearances and discussion of a multitechnique imaging approach. Radiographics. 2006; 26(2): 433-51. PMid:16549608

http://dx.doi.org/10.1148/rg.262055073

[2] Thakker RV, Newey PJ, Walls GV, et al. Clinical practice guidelines for multiple endocrine neoplasia type 1 (MEN1). J Clin Endocrinol Metab. 2012; 97: 2990-3011. PMid:22723327 http://dx.doi.org/10.1210/jc.2012-1230

[3] Twigt BA, Scholten A, Valk GD, et al. Differences between sporadic and MEN related primary hyperparathyroidism; clinical expression, preoperative workup, operative strategy and follow-up. Orphanet J Rare Dis. 2013; 50: 1-8. http://dx.doi.org/10.1186/1750-1172-8-50

[4] Castleman B, Schantz A, Roth S. Prathyroid hyperplasia in primary hyperparathyroidism, a review of 85 cases. Cancer. 1976; 38 : 1668-1675. http://dx.doi.org/10.1002/1097-0142(197610)38:4<1668::AID-CNCR2820380438>3.0.CO;2-X

[5] Rizzoli R, Green J, Marx SJ. Primary hyperparathyroidism in familial multiple endocrine neoplasia type 1. Am J Med. 1985; 78: 467. http://dx.doi.org/10.1016/0002-9343(85)90340-7

[6] Nilubol N, Weinstein L, Simonds WF, et al. Preoperative parathyroidectomy in MEN1 syndrome: is there any benefit? World J Surg. 2012; 36(6): 1368-74. PMid:22350475 http://dx.doi.org/10.1007/s00268-012-1451-1

[7] Johnson NA, Tublin ME, Ogilvie JB. Parathyroid imaging: technique and role in the preoperative evaluation of primary hyperparathyroidism. AJR Am J Roentgenol. 2007; 188(6): 1706-1715. PMid:17515397 http://dx.doi.org/10.2214/AJR.06.0938

[8] Gouveia S, Rodrigues D, Barros L, et al. Persistent primary hyperparathyroidism: an uncommon location for an ectopic gland-case report and review. Arq Bras Endocrinol Metabol. 2012; 56(6): 393-403. PMid:22990645 http://dx.doi.org/10.1590/S0004-27302012000600009

[9] Akerström G, Stålberg P. Surgical management of MEN-1 and -2: state of the art. Surg Clin North Am. 2009; 89(5): 1047-68. PMid:19836484 http://dx.doi.org/10.1016/j.suc.2009.06.016 